\title{
Wide-Area Synchronized among Big Data Sets of Railway Power Supply Dispatching Center
}

\author{
Zhijian Qu, Ruilin Zhou and Liang Zhao \\ School of Electrical Engineering, East China Jiaotong University, Nanchang, China
}

\begin{abstract}
Delicacy management of railway power supply and the density of trains increased made monitoring points increased and running changes intensify, a large number of fluctuation data need to be synchronized among different databases, but there are two problems need to be solved: (1) Existing various systems can not constitute an organic whole, information sharing across databases is difficult, integrated application is hard to begin; (2) Railway power supply management system is lack of data consistency and disaster tolerance capacity[4-6]. In order to solve these two problems, in this paper, Daffodil Replicator is a publish/subscribe message-oriented middleware that combined with database triggers to improve the reliability of the data synchronization ability, Daffodil Replicator can execute two-way synchronization between two databases which support Java Data Base Connectivity(JDBC), made data replication in different heterogeneous databases.
\end{abstract}

Keywords-data synchronized; data consistency; disaster tolerance; daffodil replicator; message-oriented middleware; database trigger; java data base connectivity; replication; heterogeneous databases

\section{INTRODUCTION}

On the one hand, railway power supply device is the relatively weak part of railway transportation, many power supply devices are easy to break down in heavy weather like thunderstorm and high wind and it will threat to transportation security, on the other hand, after speed up, the feeder current increase from 100 ampere to1000-1200 ampere rapidly, electrical load changes frequently and volatility is high, so it will generate dynamic produce data constantly, these data should be synchronized among different databases like workshop database, power station database and railway bureau database timely and accurately.

Databases designed by different department use different platform cause access interface is lack of uniform standards, data is hard to synchronized across databases; each design schema only meet the basic needs of users, the requirement of data consistency is low; many open source software and commercial software have design and performance problems.

Replicator is an open-source middleware designed for heterogeneous databases replication which is also the basis for my work. Its advantage lied in the common support for the synchronized between different types databases, however, I found that this solution still had shortcomings in the design of algorithms and performance[1], In order to improve the reliability of Replicator, combined Replicator with database triggers to realize dynamically and incrementally synchronization which laid the foundation for follow-up work.

\section{RAILWAY TRACTION POWER SUPPLY SYSTEM}

\section{A. Railway Power Network}

The railway power supply is an important part of modern electrified railway system, railway power network is composed of traction substation, feeder line, overhead line, return line and rail, etc. Its function is transform high voltage into low voltage to provide energy for signal device and locomotive[2]. The dispatching center automation dispatching and intelligent monitoring the traction networks current flow by remote terminal unit to found the fault message in time to provide key information and basically decision for the safety of railway power network[7]. With the scale of railway power network expanding continually, the number of monitoring point and fault information storage increased dramatically and it is easy to cause system response slowly even crash. Railway traction power supply system is shown as follow Figure I.

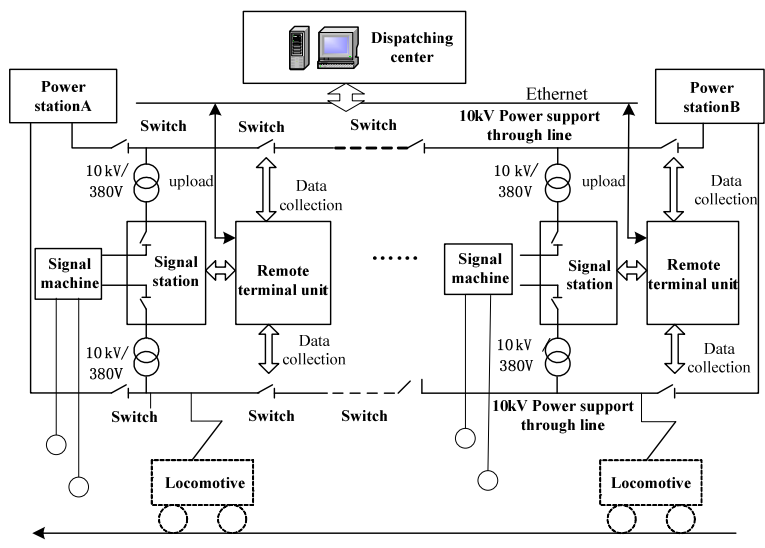

FIGURE I. RAILWAY TRACTION POWER SUPPLY SYSTEM

\section{B. The Information Flow in Railway Power Network}

Supervision control and data acquisition system as a foundation of dispatching automation system provide a large number of real-time information from RTU,FTU and STU for different departments, the real-time information transmitted to dispatching center by using remote communication interface and stored in real-time database temporarily, with data accumulation it will be stored back into historical database eventually .

Traditionally polling mode is easy to realize but the efficiency will reduce with nodes increased, in this paper, using message-oriented middleware as a bridge to connect master 
station with substation, we only need to transmit the information to message-oriented middleware instead of purpose system and it can improve concurrency of system, the information flow in railway power network is shown in Figure II.

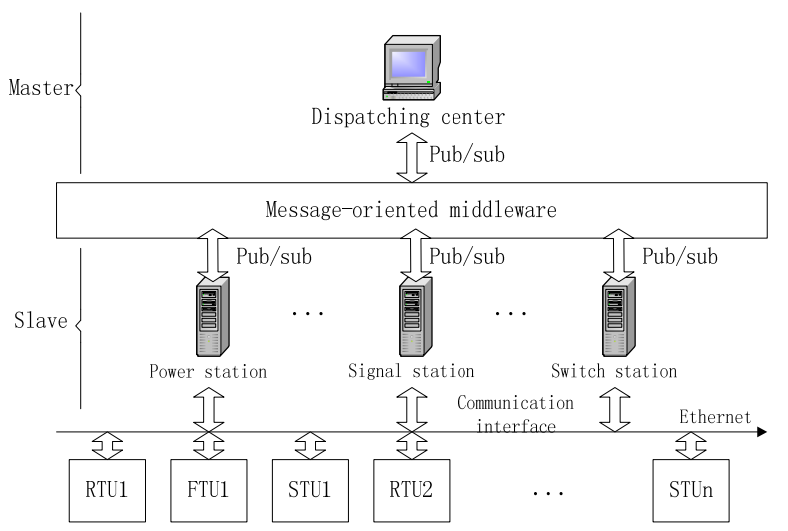

FIGURE II. THE INFORMATION FLOW IN RAILWAY POWER NETWORK

With reference to Fig. II we can see information flow have two directions are upside information flow and downside information flow, upside information mainly include state quantity like personnel message, device message, faulty message and analog quantity like voltage value and current value, downside information include remote control commands and remote parameters setting commands, as shown in the Figure III.

\begin{tabular}{|c|c|}
$\begin{array}{c}\text { Downside } \\
\text { channe1 }\end{array}$ & $\begin{array}{c}\text { Upside } \\
\text { channel } \\
\text { Remote control } \\
\text { command 1 } \\
\text { message } \\
\text { Remote parameters } \\
\text { setting command 1 }\end{array}$ \\
\hline $\begin{array}{c}\text { Remote control } \\
\text { command 2 }\end{array}$ & Device message \\
\hline $\begin{array}{c}\text { Remote parameters } \\
\text { setting command 2 }\end{array}$ & Voltage value \\
\hline$\ldots$ \\
\hline $\begin{array}{l}\text { Remote parameters } \\
\text { setting command 2 }\end{array}$
\end{tabular}

FIGURE III. THE TYPES OF INFORMATION FLOW IN RAILWAY POWER NETWORK

\section{Message-Oriented Middleware DAFFodiL REPLICATOR}

\section{A. The Structure of Daffodil Replicator}

Replicator is an open-source software that use a unified Java Data Base Connectivity (JDBC) to realize access to the underlying data of mostly DataBase Management software, Daffodil Replicator can not provide replication service for every database object like storage process, database trigger and view, it just realize two-way data synchronization between databases, Replicator adopt Subscribe/Publish model and capture the change of database by database trigger, publisher correspond to several subscribers and pack the data into XML file, XML file use a series of tags to describe data element that encapsulate different data types, because XML file provide standard and flexible extensible data format, so it is convenient to use XML file to transmit data[3], as shown in the Figure IV.

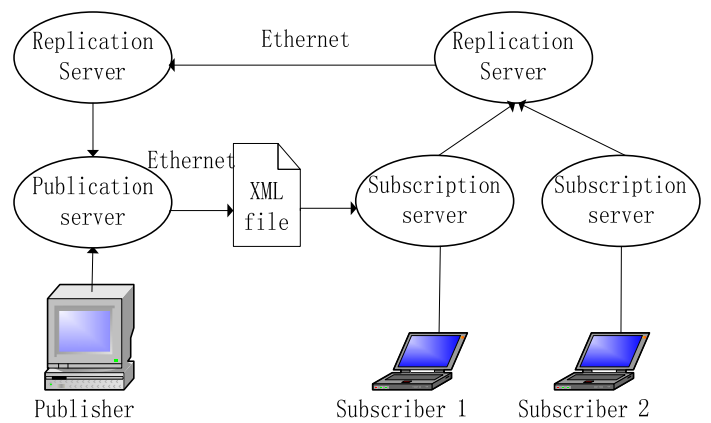

FIGURE IV. THE STRUCTURE OF DAFFODIL REPLICATOR

Replicator's mainly classes are Replicationserver, Publication and Subscription that are inherited from class UnicastRemoteObject, we can operate interface RMI remotely through RPC mechanism, interface _PubImpl extend interface remote, mainly remote invocation method is described in this interface, the mainly classes of Daffodil Replicator is shown in the Figure V.

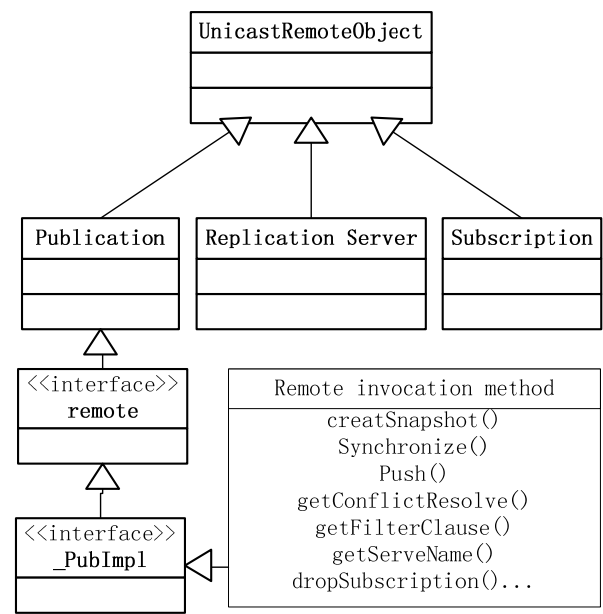

FIGURE V. MAINLY CLASSES OF DAFFODIL REPLICATOR

\section{B. The Function of Daffodil Replicator}

Replicator API consists of classes and methods to invoke synchronization operations. During runtime, Daffodil Replicator invoke following methods are called Snapshot(), Synchronize(), Pull(), Push() to realize Snapshot Replication, Merge Replication, Pull Replication and Push replication.

(1) Snapshot Replication operation transfer a complete copy of the contents of a Publisher's Publication to a Subscriber's Publication, this type of replication is usually used when a Subscriber start to synchronize the data from the Publication is 
desired.

(2) Merge Replication compares Publishers and Subscribers data and the changes made to the data by both Publisher and the Subscriber are updated or merged.

(3) Pull Replication compares Publishers and Subscribers data and the changes made to the data by the Publisher are updated in the Subscriber's database, but the changes made by the Subscriber are not reflected at Publisher's database.

(4) Push Replication compares Publishers and Subscribers data and the changes made to the data by the Subscriber are updated in the Publisher's database, but the changes made by the Publisher are not reflected at Subscriber's database.

Take merge replication as an example, the vision of "synchronized successfully" can be seen in the Figure VI.

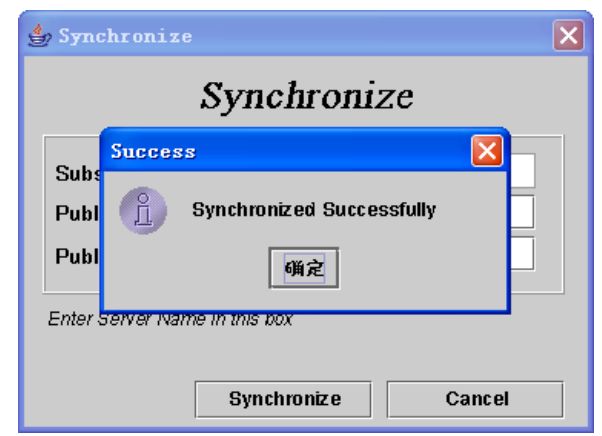

FIGURE VI. SYNCHRONIZED SUCCESSFULLY

\section{ACKNOWLEDGMENT}

This work is supported by National Natural Science Foundation of China (No. 51567008), Jiangxi Province Science Foundation for Distinguished Yong Scholars of China (No.20162BCB23045), Jiangxi Province Natural Science Foundation of China (No.20161BAB206156) and Jiangxi Province Educational Department Scientific Research Project (No.GJJ160471).

\section{REFERENCE}

[1] Hao Zhi-xiao, Wu Gang, An Optimized Window-Based Net Increment Algorithm for Database Replication, Computer Engineering \& Science, 2010, 32 (2):99-102+149.

[2] HE Zhengyou,CHENG Hongbo, Research on Healthy Management and Early Warning System for Traction Power Supply System of High-Speed Railway, Power System Technology, 2012, 36 (10):259-264.

[3] PAN Guo-wei, SONG Wei, WANG Xiang-nan, CAO Hou-ji, Research on Application of Message Oriented Middleware Based on Publish/Subscribe Model in SCADA System, Power System Technology, 2008, 32 (18):77-81.

[4] LIU Li-zhi, WU Yun-tao, Application of WCF distributed framework to middle data synchronization, Journal of Computer Applications, 2011, 31 (12):3281-3284.

[5] ZHANG Dongxia, MIAO Xin, Liu Liping, ZHANG Yan, LIU Keyan, Research on Development Strategy for Smart Grid Big Data, Proceedings of the CSEE, 2015, 35 (1):2-12.

[6] MA jian-Gang, HUANG Tao, WANG Jin-Ling, XU Gang, YE Dan, Underlying Techniques for Large-Scale Distributed Computing Oriented Publish/Subscribe System, 2006, 17 (1):134-147.
[7] QIN Y, WANG Z, WANG Y H, et al. Research and application on comprehensive monitoring and control system center of qinzang railway[J]. Journal of Transportation Systems Engineering and Information Technology, 2007, 7(2):129-134. 